
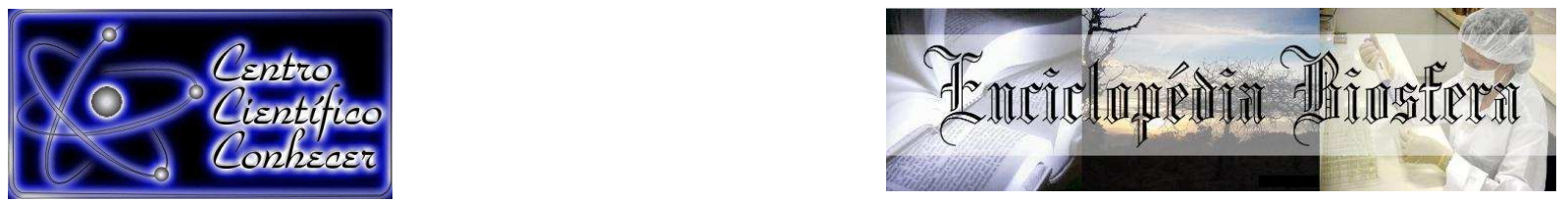

\title{
DIAGNÓSTICO DA QUALIDADE DO LEITE CRU REFRIGERADO
}

\author{
Anicézio José da Silveira Guimarães; Frederico Mendes Caetano²; Vagner \\ Rosalem ${ }^{3}$
}

1. Mestrando em Gestão Organizacional da UFG-Regional Catalão anicezio.guimaraes@ifgoiano.edu.br

2. Mestrando em Gestão Organizacional da UFG-Regional Catalão

Fredericomendescaetano1@hotmail.com

3. Doutor Docente do Programa de Pós-Graduação em Gestão Organizacional PPGGO - UFG-Regional Catalão

Vagner@hotmail.com

\author{
Recebido em: 03/10/2016 - Aprovado em: 21/11/2016 - Publicado em: 05/12/2016 \\ DOI: 10.18677/EnciBio_2016B_186
}

\begin{abstract}
Acompanhar a qualidade do leite cru refrigerado permite avaliar a eficiência dos programas voltados para a melhoria da qualidade desta matéria prima, base da cadeia de lácteos. Objetivou-se neste estudo diagnosticar a situação da qualidade do leite e verificar a adequação aos parâmetros estabelecidos pela legislação, dada sua importância socioeconômica e alimentar. Analisou-se a evolução anual da qualidade através do banco de dados, cedido por laticínio ligado ao Serviço de Inspeção Federal, contendo 20.409 amostras do leite de rebanhos bovinos do município de Catalão/GO, realizadas mensalmente pelo Laboratório Clínica do Leite, Universidade de São Paulo (USP), de 2006 a 2015. A qualidade do leite cru refrigerado melhorou cerca de $100 \%$ nos últimos 10 anos e apresentou boa qualidade em seis dos sete indicadores analisados. Apenas o requisito Contagem Bacteriana Total (CBT) indicou má qualidade com 147\% de Unidade Formadora de Colônia por mililitro de leite (UFC/mL) acima do nível máximo permitido de contaminação. Quanto a adequação dos indicadores de qualidade à legislação, $75 \%$ do leite analisado apresentou conformidade legal em todos os requisitos. A CBT determinou o desempenho da qualidade do leite, apresentando inadequação à legislação em todas as fases estabelecidas, porém com aumento de amostras em conformidade legal. Tais resultados refletiram as condições de higiene na obtenção e manutenção do produto, por isto estudos específicos poderão apontar medidas para solução do problema em questão, beneficiando toda cadeia produtiva.
\end{abstract}

RESUMO

PALAVRAS-CHAVE: diagnóstico da qualidade; leite cru refrigerado; qualidade do leite. 


\title{
MILK QUALITY DIAGNOSTIC RAW CHILLED
}

\begin{abstract}
Monitor the quality of refrigerated raw milk allows us to evaluate the effectiveness of programs aimed at improving the quality of this raw material base of the dairy chain. The aim of this study to diagnose the situation of milk quality and verify the suitability to the parameters established by the legislation, given its socio-economic importance and food. It analyzed the annual evolution of quality through the database, assigned by dairy linked to the Federal Inspection Service, containing 20.409 samples of cattle herds milk Catalan/GO, held monthly by the Clinical Laboratory Milk, University of Sao Paulo (USP) of 2006 to 2015. the quality of refrigerated raw milk has improved about $100 \%$ in the last 10 years and good quality in six of the seven indicators analyzed. Only the requirement Total Bacterial Count (TBC) indicated poor quality with 147\% Forming Cologne Unit per milliliter of milk (FCU/mL) above the maximum allowed level of contamination. The adequacy of quality indicators for legislation, $75 \%$ of the analyzed milk had legal compliance for all requirements. The TBC determined the performance of the milk quality, with inadequate legislation established at all stages, but with increased samples legal compliance. These results reflected the hygiene conditions in obtaining and maintaining the product for this specific studies may identify measures for solution of the problem in question, benefiting the entire production chain.
\end{abstract}

KEYWORDS: Quality diagnosis; Refrigerated raw milk; Quality of milk

\section{INTRODUÇÃO}

A qualidade do leite cru refrigerado é atualmente um dos temas do agronegócio brasileiro mais discutido nos últimos anos, dada a importância socioeconômica e alimentar deste produto. O leite é rico nutricionalmente, relativamente barato, de fácil acesso e, por isto, presente na mesa da maioria da população brasileira, que consome em média 180,8 litros/pessoa/ano. Esta atividade pecuária, entretanto teve início no Brasil por volta do ano de 1532, expandiu-se e historicamente tem contribuído com a fixação do homem no campo e com a geração de emprego e renda para a sociedade rural. São cerca de 1,3 milhões de propriedades produtoras de leite existentes no Brasil, que empregam cinco milhões de pessoas e movimentam aproximadamente $R \$ 100$ bilhões por ano. Os resultados da produção nos últimos anos apresentam o país como grande produtor desta matéria prima, que em 2014 produziu 35,17 bilhões de litros, tornando-se o $3^{\text {o }}$ colocado no ranking dos maiores produtores mundiais de leite (BRASIL, 2014; IBGE, 2016).

A pecuária leiteira está presente na maioria dos municípios brasileiros. 0 país possui condições bastante adequadas para a produção de leite, como extensas áreas disponíveis, variedade de alimentação, sistema produtivo diversificado, raças adaptadas, razoável tecnologia, incentivos fiscais e financeiros e indústrias para o processamento do leite (STRADIOTTI JÚNIOR et al., 2012). Entretanto, estudos mostraram que a qualidade desta matéria prima é ainda bastante deficiente na maioria das regiões brasileiras (OLIVEIRA \& GALLO, 2008). 
Além de grande produtor, o Brasil é também grande consumidor e uma das referências mundiais como exportador de lácteos. Porém, tanto os consumidores internos como os externos têm se tornado cada vez mais exigentes, condições estas que demandam da pecuária brasileira a produção de leite de boa qualidade. Assim, visando a melhoria da qualidade dos produtos lácteos em todo o território nacional, o Ministério da Agricultura, Pecuária e Abastecimento - MAPA, através da Instrução Normativa 51, de 18 de setembro de 2002 (IN51/2002), que entrou em vigor a partir de 01 de julho de 2005, estabeleceu requisitos e critérios para regulamentação da produção, armazenamento, coleta, transporte e processamento do leite. Definiu parâmetros regionais para a produção, identidade e qualidade, mas principalmente estabeleceu limites para os teores da composição físico-química níveis da composição microbiológica e datas regionais para vigorarem estes parâmetros. Neste sentido, a IN51/2002 aprovou, entre outros, o Regulamento Técnico de Identidade e Qualidade do Leite Cru Refrigerado, que define o leite como "sem outra especificação, o produto oriundo da ordenha completa, ininterrupta, em condições de higiene, de vacas sadias, bem alimentadas e descansadas" e, também o leite cru refrigerado, quando o produto citado for "refrigerado e mantido nas temperaturas constantes da Tabela 2 do presente Regulamento Técnico (...)" (DIÁRIO OFICIAL DA UNIÃO, 2002).

O produto deve ainda ser líquido, branco opalescente homogêneo, de sabor e odor característicos, porém isento de sabores e odores estranhos, ausente de neutralizantes da acidez e reconstituintes de densidade, bem como de resíduos de antibióticos e de outros agentes inibidores do crescimento microbiano Paralelamente, foi criada pelo MAPA da Rede Brasileira de Laboratórios de Controle da Qualidade do Leite - RBQL, em 2002. É constituída atualmente por 10 laboratórios, fixados em locais estratégicos em várias regiões do país e é responsável oficialmente pelas análises mensais de todo leite comercial brasileiro. (DIÁRIO OFICIAL DA UNIÃO, 2002). Posteriormente, a IN51/2002 foi substituída pela Instrução Normativa 62, de 30 de dezembro de 2011 (IN62/2011), mais flexível principalmente para os produtores, prorrogando os prazos para cumprirem as metas de qualidade do leite, embora reduzindo ainda mais os limites máximos permitidos de microrganismos contaminantes desta matéria prima (DIÁRIO OFICIAL DA UNIÃO, 2011).

Até bem pouco tempo boa parte da produção do leite no Brasil era informal e não inspecionada, a ordenha acontecia sem as condições adequadas de higiene e o produto era acondicionado em vasilhames diversos, comercializado diretamente ao consumidor ou processado na fazenda, ou ainda entregue diariamente a um laticínio (OLIVAL \& SPEXOTO, 2004; MONTANHINI \& HEIN, 2013; MOTTA et al., 2015). Tais condições são desfavoráveis à preservação da integridade do leite, predispondo-o a contaminação e degradação da sua composição físico-química, ou mesmo favorecendo o desenvolvimento microbiológico, com consequente depreciação do produto e descarte na plataforma de recepção, resultando em prejuízos para a indústria e produtores (DÜRR, 2004; VOGES et al., 2015).

Levando-se em consideração as condições mencionadas anteriormente, somando-se o rigor da legislação e as mudanças necessárias na cadeia produtiva, 
sobretudo por parte dos produtores, para adequação da qualidade do leite à legislação, coloca em cheque a qualidade do leite fresco produzido nas várias regiões do Brasil e da Microrregião Catalão. Desta forma, torna-se relevante conhecer a qualidade desta matéria prima e verificar a conformidade com a IN62/2011. Assim, objetivou-se este estudo diagnosticar a situação da qualidade do leite cru refrigerado e verificar adequação dos requisitos às IN51/2002 e $62 / 2011$.

\section{MATERIAL E MÉTODOS}

\section{Área de Estudo e População Alvo}

Este estudo se trata de uma pesquisa de leite cru refrigerado de rebanhos bovinos leiteiros, cujas amostras foram coletadas em tanques de expansão no município de Catalão/GO, de produtores cadastrados na RBQL. O agrupamento temporal e as informações são concernentes ao período de 01 de janeiro de 2006 a 31 de dezembro de 2015.

Catalão é um dos municípios da Microrregião Catalão, localizada na Região Sudeste do Estado de Goiás que, com seus 11 municípios, está entre as principais produtoras de leite do Brasil. Em 2013 foi 16 $16^{\text {a }}$ colocada no ranking nacional, entre as 558 microrregiões brasileiras produtoras de leite. O Município de Catalão/GO é o principal município produtor de leite desta microrregião e, naquele ano foi $12^{\circ}$ do ranking nacional dos cerca de 5.570 municípios produtores de leite. Possui cerca de 50 mil bovinos e 2.720 propriedades relacionadas à pecuária leiteira, das quais $70 \%$ são consideradas pequenas (até 160ha), compostas por animais de aptidão mista e por produtores com pouca formação técnica na área afim, baixa tecnologia e renda, onde predomina o sistema a pasto, sobre cerca de $50 \%$ de pastagens plantadas, porém degradas. Tais características da pecuária leiteira do município de Catalão são equiparadas à grande parte das propriedades de outras regiões brasileiras, o que a credencia como instrumento de estudo na avaliação da qualidade do leite produzido no país, pois possui semelhantes desafios de demanda de qualidade do leite e derivados.

\section{Coleta de Dados}

Utilizou-se neste estudo dados amostrais de um banco de dados resultante de análises realizadas pelo Laboratório Clínica do Leite, do Departamento de Zootecnia da Escola Superior de Agricultura "Luiz de Queiroz" (USP/ESALQ), Piracicaba/SP, pertencente à RBQL. O banco de dados foi cedido por um laticínio ligado ao Serviço de Inspeção Federal (SIF), totalizando 20.409 amostras, que continham informações completas, por produtor ou tanque comunitário, dos teores de gordura - GOR, lactose - LAC, proteína - PROT, extrato seco total - EST e extrato seco desengordurado - ESD e, dos níveis de contagem de células somáticas - CCS e contagem bacteriana total - CBT, referidos neste estudo como requisitos ou indicados da qualidade do leite. Por isto, o número de amostras foi igual para todos os indicadores ou requisitos de qualidade do leite. As amostragens e análises laboratoriais seguiram as instruções da legislação e do respectivo laboratório. 


\section{Análise de Dados}

Para diagnosticar a qualidade do leite foi realizada uma análise quantitativa dos dados, calculando-se as médias geométricas anuais para cada indicador de qualidade (GOR, PROT, LAC, EST, ESD, CCS e CBT) e, a partir destas, as médias gerais dos indicadores no período em estudo. Estas médias gerais foram comparadas com os valores dos parâmetros dos requisitos determinados pela legislação, correspondentes à 3⿳⺈冂大 Fase da IN62/2011.

Para a verificação da adequação dos requisitos da qualidade do leite à legislação, empregou-se uma análise descritiva, calculando-se das médias geométricas dos valores de cada requisito, referentes aos três meses imediatamente anteriores às datas para vigorar os novos limites estabelecidos pela legislação. Estas médias foram: comparação com os valores dos respectivos parâmetros em cada fase de ajuste determinadas pelas IN51/2002 e 62/2011. As análises estatísticas foram realizadas através do software Excelß for Windows da Microsoft e os resultados apresentados em forma de gráfico e tabela.

As Instruções Normativas 51/2002 e 62/2011 constituem instrumento referencial neste estudo, pois foi através delas que o MAPA fixou parâmetros para determinar a qualidade do leite cru refrigerado em cada região brasileira. Para as Regiões Sul, Sudeste e Centro-Oeste, os requisitos da qualidade do leite referentes à composição físico-química (ou centesimal) utilizados neste estudo, tiveram assim definidos os teores mínimos: 3,0\% de gordura, 2,9\% de proteína, $4,3 \%$ de lactose, $8,4 \%$ de ESD e $11,4 \%$ de EST. Estes valores permanecem inalterados desde que foram fixados inicialmente. Os índices máximos medidos permitidos de CCS e CBT vigentes são 500 mil células somáticas por mililitro de leite $(\mathrm{CS} / \mathrm{mL})$ e 300 mil unidade formadora de colônia por mililitro de leite (UFC/mL), respectivamente, porém tem passado por ajustes em etapas preestabelecidas pela legislação, como podem ser observados no Quadro 1, que apresenta ainda as fases ou etapas das mudanças de critérios das respectivas instruções normativas, os novos limites dos parâmetros e as datas para vigorarem e os critérios mínimos a serem adotados para as amostragens e análises (DIÁRIO OFICIAL DA UNIÃO, 2002 e 2011).

QUADRO 1 - Parâmetros de CBT e CCS em leite cru refrigerado homologados

\begin{tabular}{|c|c|c|c|c|c|c|c|}
\hline \multirow{4}{*}{$\begin{array}{l}\text { Índice medido } \\
\text { (por propriedade ou } \\
\text { tanque comunitário; } \\
\text { minimo } 1 \text { análise } \\
\text { mensal; média geo- } \\
\text { métrica de } 3 \text { meses) }\end{array}$} & \multicolumn{7}{|c|}{ Fases - Datas para vigorar - Limites máximos } \\
\hline & \multicolumn{2}{|c|}{ IN51/2002 } & \multicolumn{4}{|c|}{ IN62/2011 } & IN7/2016 \\
\hline & $1^{\text {a } F a s e}$ & $2^{a} \mathrm{Fa}$ & 5 & $2^{\mathrm{a}}$ Fase & $3^{\text {a Fase }}$ & a Fase & \\
\hline & $\begin{array}{c}\text { Até } \\
01 / 7 / 2005\end{array}$ & $\begin{array}{c}01 / 7 / 2005 \\
a \\
31 / 12 / 2008\end{array}$ & $\begin{array}{c}01 / 7 / 2008 \\
a \\
31 / 12 / 2011\end{array}$ & $\begin{array}{c}01 / 1 / 2012 \\
a \\
30 / 6 / 2014\end{array}$ & $\begin{array}{c}01 / 7 / 2014 \\
a \\
30 / 6 / 2016\end{array}$ & & \\
\hline $\mathrm{CE}$ & & 1.000 & 750 & 00 & 300 & & \\
\hline $\operatorname{CCS}(\mathrm{CS} / \mathrm{mL})$ & 1.000 .000 & 1.000 .000 & 750.000 & 600.000 & 500.000 & 400.000 & 400.000 \\
\hline
\end{tabular}

FONTE: Diário Oficial da União, 2011 e 2016. Adaptado pelos Autores.

(*) A 4ª Fase da IN62/2011 foi prorrogada até 01/7/2018, através da IN7/2016 do MAPA.

Conforme demonstrado no Quadro 1, os parâmetros da 3모 Fase da IN62 permanecerão vigentes até 01 de julho de 2018 nas Regiões S, SD e CO, de ENCICLOPÉDIA BIOSFERA, Centro Científico Conhecer - Goiânia, v.13 n.24; p.1821 2016 
acordo com a Instrução Normativa n‥ 7, de 3 maio 2016 do MAPA. Para verificação da adequação destes requisitos, o leite de cada produtor ou tanque comunitário deve ser analisado mensalmente por um laboratório pertencente à Rede Brasileira de Laboratórios de Controle da Qualidade do Leite - RBQL, criada para este fim em várias regiões do país pelo MAPA (DIÁRIO OFICIAL DA UNIÃO, 2011). Os resultados, depois de alimentar um banco de dados da RBQL, são encaminhados mensalmente aos respectivos produtores e aos laticínios que os formalizaram no sistema do MAPA para providências, quando for o caso.

\section{RESULTADOS E DISCUÇÃO}

\section{A Qualidade do Leite Cru Refrigerado}

A evolução da qualidade do leite cru refrigerado, através dos números de amostras e das médias geométricas de cada requisito analisado durante o período temporal em estudo, está expressa na Tabela 1. Estes resultados se encontram tabulados anualmente, apresentando-se ainda a média geral das análises, do número de amostras e respectivos percentuais em relação à amostragem total. Segue-se ainda, os limites em vigor dos requisitos estabelecidos pela IN62/2011, do MAPA, para as Regiões Centro-Sul do Brasil.

TABELA 1 - Limites em vigor e médias geométricas dos requisitos - 2006 a 2015.

\begin{tabular}{|c|c|c|c|c|c|c|c|c|c|}
\hline \multirow{2}{*}{ ANOS } & \multirow{2}{*}{$\begin{array}{c}\text { Gordura } \\
\% \\
\end{array}$} & \multirow{2}{*}{$\begin{array}{c}\text { Proteína } \\
\% \\
\end{array}$} & \multirow{2}{*}{$\begin{array}{c}\text { Lactose } \\
\%\end{array}$} & \multirow{2}{*}{$\begin{array}{c}\text { EST } \\
\% \\
\end{array}$} & \multirow{2}{*}{$\begin{array}{c}\text { ESD } \\
\% \\
\end{array}$} & \multirow{2}{*}{$\begin{array}{c}\text { CCS } \\
\times 1000 \mathrm{CS} / \mathrm{mL}\end{array}$} & \multirow{2}{*}{$\begin{array}{c}\text { CBT } \\
\times 1000 \mathrm{UFC} / \mathrm{mL}\end{array}$} & \multicolumn{2}{|c|}{ Amostras } \\
\hline & & & & & & & & $\mathrm{N}^{\circ}$ & $\%$ \\
\hline 2006 & 3,7 & 3,3 & 4,5 & 12,4 & 8,8 & 292 & 582 & 3.125 & 15,3 \\
\hline 2007 & 3,6 & 3,2 & 4,6 & 12,4 & 8,7 & 351 & 1034 & 2.494 & 12,2 \\
\hline 2008 & 3,7 & 3,3 & 4,5 & 12,4 & 8,8 & 346 & 1131 & 3.582 & 17,6 \\
\hline 2009 & 3,6 & 3,3 & 4,6 & 12,4 & 8,8 & 332 & 850 & 3.187 & 15,6 \\
\hline 2010 & 3,6 & 3,3 & 4,6 & 12,4 & 8,8 & 418 & 515 & 1.729 & 8,5 \\
\hline 2011 & 3,6 & 3,3 & 4,5 & 12,4 & 8,8 & 411 & 487 & 1.555 & 7,6 \\
\hline 2012 & 3,6 & 3,3 & 4,6 & 12,4 & 8,8 & 374 & 576 & 1.425 & 7,0 \\
\hline 2013 & 3,3 & 3,2 & 4,6 & 12,1 & 8,8 & 363 & 953 & $* 421$ & 2,1 \\
\hline 2014 & 3,5 & 3,3 & 4,6 & 12,3 & 8,8 & 350 & 723 & 1.598 & 7,8 \\
\hline 2015 & 3,5 & 3,3 & 4,6 & 12,4 & 8,9 & 349 & 559 & 1.293 & 6,3 \\
\hline Médias & 3,6 & 3,3 & 4,6 & 12,4 & 8,8 & 359 & 741 & \multirow{2}{*}{\multicolumn{2}{|c|}{ Total: }} \\
\hline Limites & 3,0 & 2,9 & 4,3 & 11,4 & 8,4 & 500 & 300 & & \\
\hline $\begin{array}{c}\text { Extrapolação } \\
\text { ao limite }\end{array}$ & $20 \%$ & $14 \%$ & $7 \%$ & $9 \%$ & $5 \%$ & $-28 \%$ & $147 \%$ & 20.409 & 100 \\
\hline
\end{tabular}

FONTE: Os autores, (2016).

$\left(^{*}\right)$ - No ano de 2013 continham dados somente de outubro a dezembro.

LEGENDA: EST: estrato seco total, ESD: estrato seco desengordurado, CBT: contagem bacteriana total e CCS: contagem de células somáticas.

Observa-se na Tabela 1 que o número de amostras diminuiu em mais de $142 \%$ entre o primeiro ano do período analisado (2006) e o último (2015). As amostras correspondem às análises mensais do leite cru refrigerado de cada produtor ou tanque comunitário, como preconiza a legislação. Entretanto, verificou-se no banco de dados, além de uma diminuição correspondente do número de produtores, a falta de informações de resultados de análises em quase todos os meses e, às vezes, de todos os produtores em determinado mês ao longo do período, como foi o caso do ano de 2013, que continha informações apenas dos últimos três meses. 
Os requisitos da composição centesimal (gordura, lactose, proteína, estrato seco total e estrato seco desengordurado) apresentaram resultados anuais estáveis ao longo de todo o período. Quanto aos requisitos da composição microbiológica, a CCS apresentou relativa estabilidade ao longo do período, porém com ligeiro aumento (máximo 24\%) nos anos de 2010 a 2013. A CBT foi o único requisito que se mostrou bastante instável, com aumento de até $107 \%$ nos anos de 2007 a 2009 e de 75\% entre 2012 a 2013, em relação aos demais anos. A CBT foi também o requisito, cuja média geral do período analisado estava em desconformidade com os parâmetros legais. A média geral deste indicativo foi de $741 \mathrm{mil} U \mathrm{FC} / \mathrm{mL}$, quase $150 \%$ acima do limite máximo permitido pela legislação para a Região Centro-Oeste.

A Figura 1 apresenta o percentual de amostras conforme o escore de CBT ao longo do período analisado, uma vez que este foi o único indicador da qualidade do leite que não apresentou adequação à legislação.

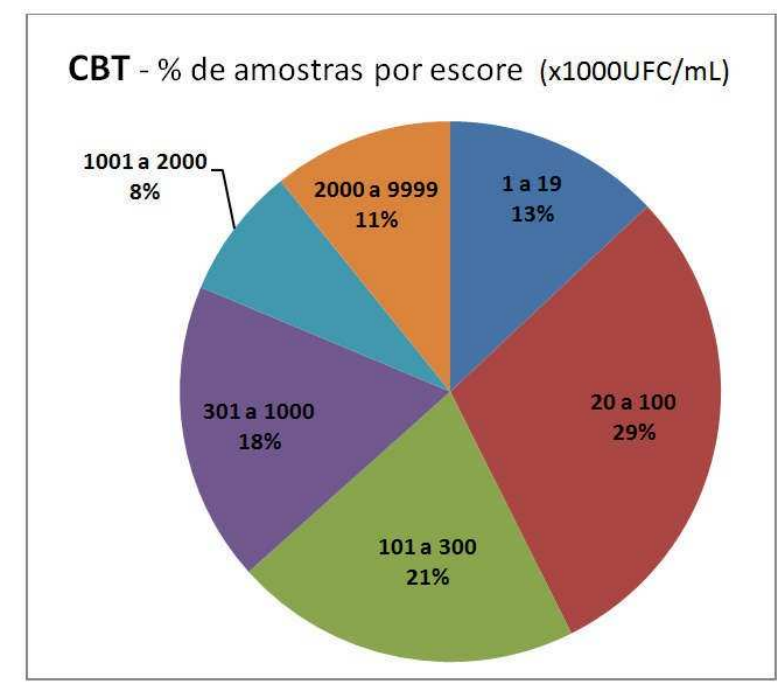

FIGURA 1 - Percentual de amostras conforme Escore de CBT.

FONTE: Os autores, 2016.

A Figura 1 mostra que $63 \%$ das amostras de CBT estão adequadas à legislação, ou seja, no máximo $300 \mathrm{mil} U \mathrm{UFC} / \mathrm{mL}$. Do total de amostras (42\%) apresentam valores máximos de $100 \mathrm{mil}$ UFC/mL. dos quais $29 \%$ estão com valores máximos de $100 \mathrm{mil} \mathrm{UFC/mL}$. Isto constitui indicativo positivo para aumento da melhoria da qualidade do leite produzido na área objeto deste estudo.

De acordo com as IN51 e 62, após 01 de julho de 2008, no centro-sul brasileiro os níveis de CCS e CBT não poderiam ser superiores a 750 mil CS ou UFC por mililitro de leite cru refrigerado comercial. Este limite deveria cair para 600 mil a partir de 01 de janeiro de 2012 e, a partir de 01 de julho de 2014, o leite cru refrigerado poderia ter no máximo $300 \mathrm{mil} U F C / \mathrm{mL}$ para CBT e $500 \mathrm{mil} \mathrm{CS} / \mathrm{mL}$ para CCS, limites ainda em vigor, assegurados pela IN7/2016 do MAPA (DIÁRIO OFICIAL DA UNIÃO, 2011 e 2016). Tal normativa era aguardada com expectativa pelo setor e reflete o entendimento do governo quanto à dificuldade de adequação da qualidade do leite à legislação, sobretudo por parte dos produtores. 
Adequação dos Indicadores da Qualidade do Leite à Legislação

A IN62/2011 determina que a conformidade da qualidade do leite cru refrigerado aos parâmetros por ela estabelecidos, correspondem às médias geométricas das análises dos requisitos nos últimos três meses, do leite de cada produtor ou tanque comunitário (DIÁRIO OFICIAL DA UNIÃO, 2011). Para verificar a conformidade legal das amostras utilizadas neste estudo, foram verificadas as médias dos três últimos meses que antecederam as datas limites para vigorar os novos parâmetros da qualidade do leite cru refrigerado, instituídos para a Região Sul, Sudeste e Centro-Oeste do Brasil. A Tabela 2 apresenta uma análise descritiva da situação das amostras em relação à legislação vigente, em cada etapa estabelecida pelas IN51 e 62, ao longo do período em estudo.

TABELA 2 - Médias geométricas dos requisitos, limites legais e datas para vigorar.

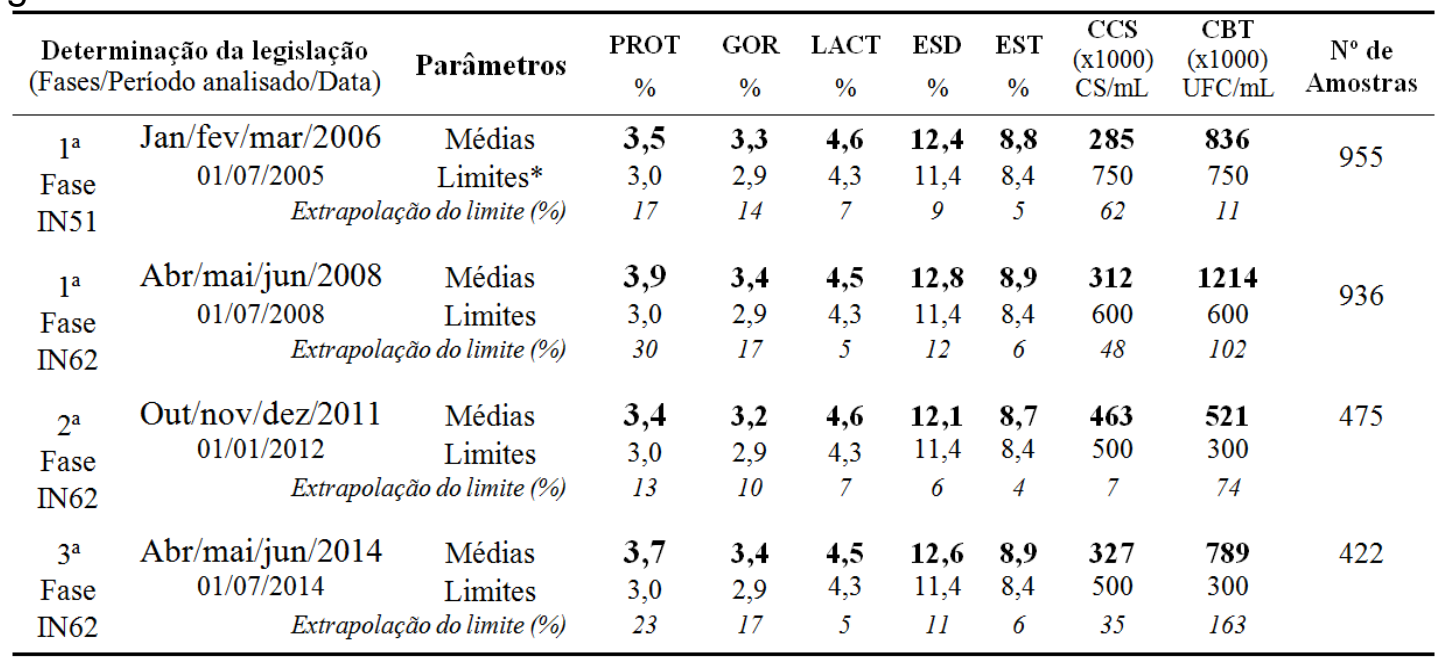

FONTE: Diário Oficial da União, 2002 e 2011. Adaptado pelos autores. CCS.

$\left(^{*}\right)$ Limites: mínimos para proteína, gordura, lactose, ESD e EST e, máximo para CBT e

Conforme é demonstrado na Tabela 2, todos os requisitos da composição centesimal estiveram adequados aos parâmetros estabelecidos pelas Instruções Normativas, em todas as respectivas datas para vigorar. O enquadramento destes requisitos se mantiveram relativamente estáveis ao longo do período, com variação apenas da gordura, porém positiva, principalmente na $1^{\underline{a}}$ e $3^{\underline{a}}$ Fases da IN62, em $30 \%$ e $23 \%$, respectivamente. Quanto à composição microbiológica, a CCS também se manteve enquadrada em todas as etapas, porém demonstrando aumento das médias geométricas e, consequentemente, reduzindo a diferença positiva para os limites máximos permitidos, ao longo das etapas determinadas

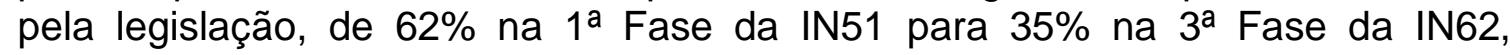
chegando a $7 \%$ na Fase anterior.

A CBT foi o único requisito que se manteve fora do enquadramento, 
inclusive desde o início do período analisado. As médias geométricas deste requisito apresentaram variação e redução entre a primeira e a última etapa de ajustes, porém não adequou aos limites estabelecidos pelas Instruções Normativas. A extrapolação deste requisito foi de desconformidade, chegando a $163 \%$ acima do limite máximo permitido na 3aㅡ Fase da IN62.

A verificação da conformidade do leite com a legislação pode ser ainda observada em detalhamento nas análises estatísticas. A Tabela 3 mostra a situação do enquadramento dos indicadores em cada etapa determinada pela legislação. Demonstra o percentual de amostras em conformidade e em desconformidade aos limites estabelecidos pelas IN51 e 62, nas respectivas datas para vigorar.

TABELA 3 - Enquadramento dos indicadores da qualidade do leite à legislação.

\begin{tabular}{|c|c|c|c|c|c|c|c|c|c|}
\hline \multicolumn{2}{|c|}{ Enquadramento } & \multirow{2}{*}{$\begin{array}{l}\text { Requisitos } \\
\text { Situação }\end{array}$} & PROT & \multirow[t]{2}{*}{ GOR } & \multirow{2}{*}{\multicolumn{3}{|c|}{$\begin{array}{c}\text { LACT ESD EST } \\
\% \text { de amostras }\end{array}$}} & \multirow[t]{2}{*}{ CCS } & \multirow[t]{2}{*}{ CBT } \\
\hline Etapas & Datas limite & & & & & & & & \\
\hline $\begin{array}{l}1^{\text {a }} \text { Fase } \\
\text { IN51 }\end{array}$ & 01/07/2005 & $\begin{array}{l}\text { Conformidade } \\
\text { Desconformidade }\end{array}$ & $\begin{array}{l}89,6 \\
10,4\end{array}$ & $\begin{array}{c}95,8 \\
4,2\end{array}$ & $\begin{array}{c}95,5 \\
4,5\end{array}$ & $\begin{array}{c}95,3 \\
4,7\end{array}$ & $\begin{array}{c}91,8 \\
8,2\end{array}$ & $\begin{array}{l}86,1 \\
13,9\end{array}$ & $\begin{array}{l}38,0 \\
62,0\end{array}$ \\
\hline $\begin{array}{l}1^{\text {a }} \text { Fase } \\
\text { IN62 }\end{array}$ & 01/07/2008 & $\begin{array}{l}\text { Conformidade } \\
\text { Desconformidade }\end{array}$ & $\begin{array}{c}96,7 \\
3,3\end{array}$ & $\begin{array}{c}97,5 \\
2,5\end{array}$ & $\begin{array}{c}93,5 \\
6,5\end{array}$ & $\begin{array}{c}97,1 \\
2,9\end{array}$ & $\begin{array}{c}96 \\
4\end{array}$ & $\begin{array}{l}83,4 \\
16,6\end{array}$ & $\begin{array}{l}53,5 \\
46,5\end{array}$ \\
\hline $\begin{array}{l}2^{\mathrm{a}} \text { Fase } \\
\text { IN62 }\end{array}$ & 01/01/2012 & $\begin{array}{l}\text { Conformidade } \\
\text { Desconformidade }\end{array}$ & $\begin{array}{l}81,1 \\
18,9\end{array}$ & $\begin{array}{c}97,9 \\
2,1\end{array}$ & $\begin{array}{c}98,7 \\
1,3\end{array}$ & $\begin{array}{c}91,2 \\
8,8\end{array}$ & $\begin{array}{c}93,7 \\
6,3\end{array}$ & $\begin{array}{l}72 \\
28\end{array}$ & $\begin{array}{l}72,2 \\
27,8\end{array}$ \\
\hline $\begin{array}{c}3^{a} \text { Fase } \\
\text { IN62 }\end{array}$ & 01/07/2014 & $\begin{array}{l}\text { Conformidade } \\
\text { Desconformidade }\end{array}$ & $\begin{array}{c}90,7 \\
9,3\end{array}$ & $\begin{array}{c}97,6 \\
2,4\end{array}$ & $\begin{array}{c}96,2 \\
3,8\end{array}$ & $\begin{array}{c}95,7 \\
4,3\end{array}$ & $\begin{array}{c}98,3 \\
1,7\end{array}$ & $\begin{array}{l}81,5 \\
18,5\end{array}$ & $\begin{array}{l}75,6 \\
24,4\end{array}$ \\
\hline
\end{tabular}

FONTE: Diário Oficial da União (2002 e 2011), adaptado pelos autores; Os autores, 2016.

$\mathrm{Na}$ Tabela 3 é possível observar aumento da conformidade do leite analisado durante o período temporal em estudo em quase todos os requisitos. A CBT foi o requisito que determinou o enquadramento, pois teve a menor porcentagem de amostras em conformidade com a legislação em todas as etapas analisadas. Porém apresentou aumento a partir do início do estudo, de $38 \%$ na $1^{\text {a }}$ data limite para $75,6 \%$ na última, em 01/07/2014. Os demais requisitos se mantiveram estáveis, com ligeiro aumento. Somente a CCS diminuiu, mas mesmo assim permaneceu com percentual de mais de $81 \%$ das amostras em conformidade com a legislação.

As Figuras 2 e 3 apresentam as performances dos requisitos por ocasião das datas limites para vigorar, em análises. A Figura 2 contem as informações das amostras em conformidade legal, enquanto a Figura 3 refere-se à desconformidade. 


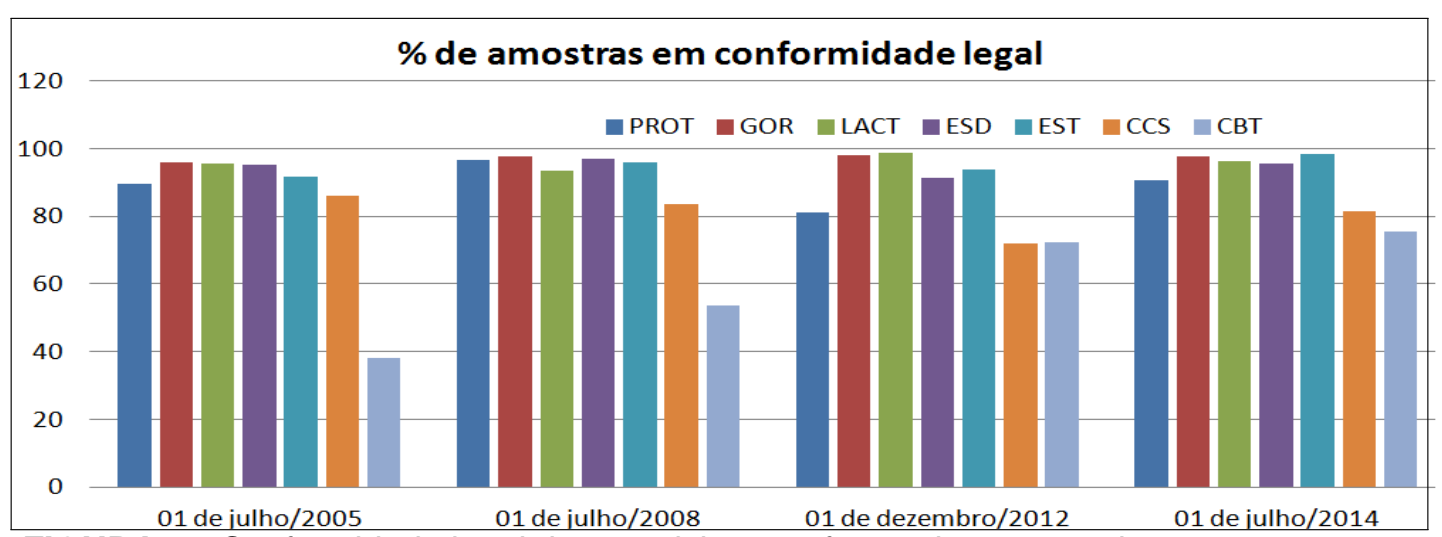

FIGURA 2 - Conformidade legal dos requisitos conforme datas para vigorar.

FONTE: Os autores, 2016.

LEGENDA: PRO: proteína, GOR: gordura, LAC: lactose, EST: estrato seco total; ESD: estrato seco desengordurado, CBT: contagem bacteriana total, CCS: contagem de células somáticas.

A Figura 2 demonstra o comportamento diferenciado da CBT, sendo menor que os demais requisitos, porém com aumento da conformidade ao longo do período analisado. Os demais indicadores mantém níveis maiores de amostras conformes, porém com certa estabilidade. Percebe-se nas colunas da CCS uma pequena variação do número de amostras em conformidade entre as quatro etapas analisadas.

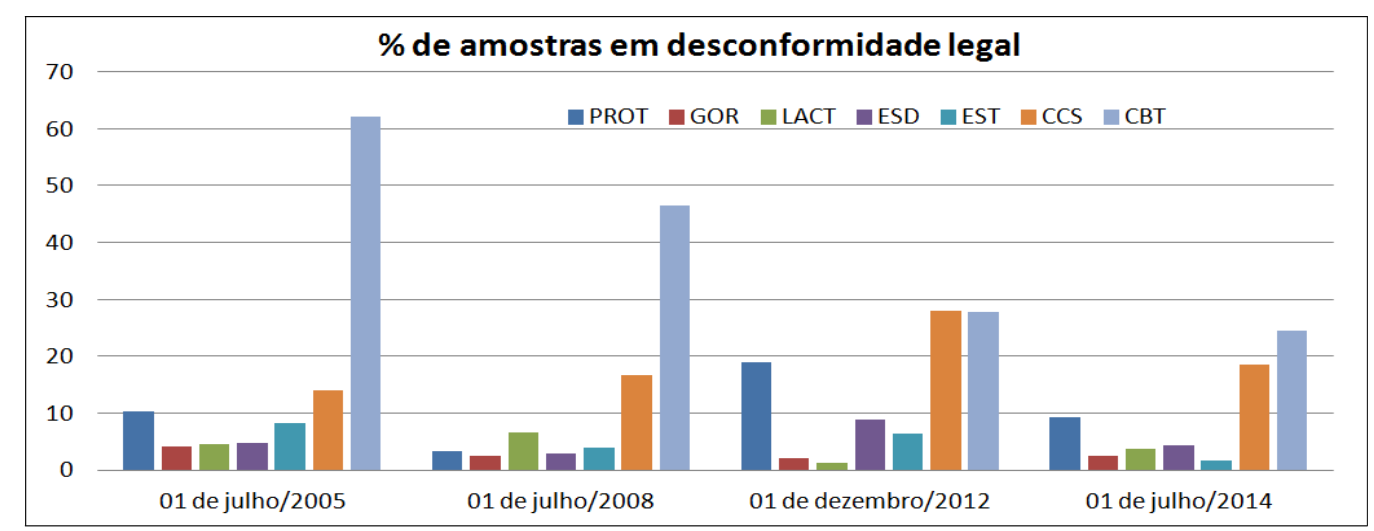

FIGURA 3 - Requisitos em desconformidade legal segundo as datas para vigorar. FONTE: Os autores, 2016.

A Figura 3 evidencia a diminuição das amostras em desconformidade legal, comparando-se dados de 01/07/2005 e 01/07/2014, e o elevado nível de amostras desconformes da CBT em relação aos demais requisitos, porém com redução ao longo do período analisado. Apresenta também um aumento, ainda que modesto, das amostras em desconformidade da CCS, sobretudo nas últimas datas analisadas. Os demais requisitos se apresentam estáveis e em níveis baixos de amostras desconformes aos parâmetros legais vigentes nas respectivas datas para vigorar.

A composição físico-química do leite cru refrigerado está relacionada principalmente com a genética do animal, alimentação do rebanho e cuidados ENCICLOPÉDIA BIOSFERA, Centro Científico Conhecer - Goiânia, v.13 n.24; p.1826 2016 
higiênico-sanitários empregados na produção, sendo que a quantidade destes componentes determina o rendimento do leite na fabricação de derivados (RODRIGUES et al., 2013). Por outro lado, a CCS indica a saúde do animal e a CBT reflete as condições de higiene por ocasião da obtenção e armazenamento do produto. Quanto maior a presença de CBT no leite, maior a contaminação e a possibilidade de degradação e o risco alimentar do consumidor (SANTOS \& FONSECA, 2007; VALLIN et al., 2009; CALLEFE \& LANGONI, 2015).

Vários são os fatores que influenciam na qualidade do leite. Dentre os principais estão o potencial genético, raça e idade do animal, manejo e sanidade do rebanho, quantidade e qualidade dos alimentos fornecidos aos animais e aqueles relacionados ao armazenamento e transporte do produto (STRADIOTTI JÚNIOR et al., 2012; MONTANHINI et al., 2013; DIAS et al., 2015), que possuem maior dependência do meio externo, como animais disponíveis, investimentos financeiros, condições climáticas e estruturação e organização do setor lácteo. Porém, cruciais são a higiene na ordenha e as condições para a obtenção do leite, que são dependentes dos produtores e ordenhadores.

A qualidade do leite tem reflexos na produção e no consumo de derivados lácteos e interfere no rendimento industrial, no tempo de prateleira, na segurança alimentar e no preço do produto pago ao produtor (SILVA et al. 2014). O leite de boa qualidade, no entanto, pode agregar valor industrial e financeiro ao produto, proporcionar vantagens aos produtores, indústrias e consumidores, além de favorecer o desenvolvimento do setor lácteo (OLIVEIRA et al., 2005; MENEZES et al., 2014; SEBRAE, 2015).

Neste sentido, o acompanhamento da situação da qualidade do leite demonstrou que é ferramenta indispensável na avaliação da eficiência dos programas voltados para o aumento do volume de produção e do controle e incentivos à melhoria da qualidade do leite, que é a matéria prima base da cadeia de lácteos. Dada a importância da atividade leiteira para a economia brasileira, faz-se necessário ao governo e entidades do setor lácteo desenvolverem políticas que estimulem os produtores a investirem na capacitação técnica e nas boas práticas de produção, com a finalidade da melhoria da qualidade do leite cru refrigerado. Visto que a CCS e a CBT foram os requisitos de maior influência na qualidade do leite avaliado nesta pesquisa, estudos mais específicos poderão apontar medidas mais precisas para solução do problema em questão, com benefícios expressivos para toda cadeia produtiva.

\section{CONCLUSÕES}

Os resultados encontrados para as médias gerais dos indicadores de qualidade, analisados neste estudo, evidenciaram que a qualidade do leite cru refrigerado melhorou cerca de $100 \%$ nos últimos 10 anos. Contudo, apresenta boa qualidade em seis dos sete indicadores analisados, sendo que apenas o requisito CBT indica má qualidade, $147 \%$ de UFC/mL acima do nível máximo permitido de contaminação.

Quanto a adequação dos indicadores de qualidade à legislação, houve saldo positivo na quantidade de amostras adequadas e pelo menos $75 \%$ do leite analisado apresentou conformidade legal em todos os requisitos. Os resultados 
revelaram ainda que a CBT foi o requisito determinante no desempenho da qualidade desta matéria prima, apresentando inadequação à legislação em todas as fases estabelecidas, porém ocorreu aumento do número de amostras em conformidade legal deste indicador, considerando-se o início de 2006 para o final de 2015. Estes resultados refletem principalmente o manejo do rebanho e das instalações de produção e as condições de higiene na obtenção e manutenção do produto.

\section{REFERÊNCIAS}

BRASIL. Assessoria de Gestão Estratégica. Ministério da Agricultura, Pecuária e Abastecimento. Plano mais pecuária. Brasília, 2014.p.8,9. Disponível em: $<\mathrm{http}$ ://www.agricultura.gov.br/arq_editor/file/Ministerio/Publicacao_v2.pdf> Acesso em: 9 ago. 2016.

BRASIL. Instituto Brasileiro de Geografia e Estatística. Produção da Pecuária Municipal, v. 42. Brasília, 2014. Disponível em: <http://biblioteca.ibge.gov.br/ visualizacao/periodicos/84/ppm_2014_v42_br.pdf>. Acesso em: 25 jul. 2016.

CALLEFE, J. L. R.; LANGONI, H. Qualidade do leite: uma meta a ser atingida. Revista Veterinária e Zootecnia, Botucatu, SP. Jun. 2015. 22(2): 151-162. Disponível em: <http://www.fmvz.unesp.br/rvz/index.php/rvz/article/view/929> Acesso em: 22 ago. 2016.

DIÁRIO OFICIAL DA UNIÃO. Instrução Normativa N.37, de 18 de abril de 2002. 19 abr. 2002. Disponível em: <http://sistemasweb.agricultura.gov.br/sislegis/action/ detalhaAto.do?method=consultarLegislacaoFederal>. Acesso em: 12 ago. 2016.

2002. Seção I p.13-22.

Instrução Normativa N.51, de 20 de setembro de 2002. 21 de set. Instrução Normativa N.62, de 29 de dezembro de 2011. 30 dez. 2011.

Seção 1, p. 1-24.

Instrução Normativa n’. 7, de 03 de maio de 2016 . 04 mai/2016.

DIAS, M.; ASSIS, A. C. F.; NASCIMENTO, V. A.; SAENZ, E. A. C.; LIMA, L. A. Sazonalidade dos componentes do leite e o programa de pagamento por qualidade. Enciclopédia Biosfera, Centro Científico Conhecer, Goiânia, v.11 n.21; p. 2015. Disponível em: $<$ http://www.conhecer.org.br/enciclop/2015b/agrarias/

Sazonalidade\%20dos\%20componentes.pdf> Acesso em: 22 ago. 2016.

DÜRR, J. W. Programa nacional de melhoria da qualidade do leite: uma oportunidade única. In: DÜRR, J.W., CARVALHO, M.P., SANTOS, M.V. (Eds.) 0 
Compromisso com a Qualidade do Leite. Passo Fundo: Editora Universidade de Passo Fundo, 2004, v.1, p. 38-55.

MENEZES, M. F. C.; SIMEONI, C. P.; ETCHEPARE, M. A.; HUERTA, K.; BORTOLUZZI, D. P.; MENEZES, C. R. Microbiota e conservação do leite. Revista Eletronica em Gestão, Educação e Tecnologia Ambiental - REGET - v. 18. Ed. Especial Mai. 2014, p. 76-89. Disponível em: <periodicos.ufsm.br/reget/article/ download/13033/pdf> DOI: http://dx.doi.org/10.5902/2236117013033.

MOTTA, R. G.; SILVA, A. V.; GIUFFRIDA, R.; SIQUEIRA, A. K.; PAES, A. C.; MOTTA, I. G.; LISTONI, F. J. P.; RIBEIRO, M. G. Indicadores de qualidade e composição de leite informal comercializado na região Sudeste do Estado de São Paulo. Pesquisa Veterinária Brasileira. 35(5):417-423, mai. 2015. Disponível em: <http://www.scielo.br/pdf/pvb/v35n5/1678-5150-pvb-35-05-00417.pdf>

DOI: 10.1590/S0100-736X2015000500005.

MONTANHINI, M. T. M.; HEIN, K. K. Qualidade do leite cru comercializado informalmente no município de Piraí do Sul, Estado do Paraná, Brasil. Revista do Instituto Laticínios Cândido Tostes, Juiz de Fora, v. 68, n. 393, p. 10-14, jul/ago., 2013.2 Disponível em: <https://www.revistadoilct.com.br/rilct/article/view/31/35>

DOI: http://dx.doi.org/10.5935/2238-6416.20130030.

MONTANHINI, M. T. M.; MORAES, D. H. M.; NETO, R M. Influência da contagem de células somáticas sobre os componentes do leite. Revista do Instituto de Laticínios Cândido Tostes, Juiz de Fora, v. 68, n. 392, p. 18-22, mai./jun., 2013. Disponível em: <https://www.revistadoilct.com.br/rilct/article/view/25/331> DOI: http://dx.doi.org/10.5935/2238-6416.20130024.

OLIVAL, A. A.; SPEXOTO, A. A.. Leite informal no Brasil: aspectos sanitários e educativos. Revista Higiene Alimentar, 18(119):12-17, abr. 2004.

OLIVEIRA, C. A. F.; FONSECA, L. F. L.; GERMANO, P. M. L. Aspectos relacionados à produção, que influenciam a qualidade do leite. Revista Higiene Alimentar. São Paulo, SP, 2005.

OLIVEIRA, R. P. S.; GALLO, C. R. Condições microbiológicas e avaliação da pasteurização em amostras de leite comercializadas no município de Piracicaba, SP. Revista Higiene Alimentar, v. 22, n. 161, p. 112-115, São Paulo, 2008. Disponível em: <http://www.teses.usp.br/teses/disponiveis/11/11141/tde18072005-164621/en. php> DOI: 10.11606/D.11.2005.tde-18072005-164621.

RODRIGUES, E.; CASTAGNA, A. A.; DIAS, M. T.; ARONOVICH, M. Qualidade do leite e derivados: processos, processamento tecnológico e índices. PesagroRio. Programa Rio Rural: Manual Técnico 37. Niterói, RJ, 2013. 
SANTOS, M. V.; FONSECA, L. F. L.. Estratégias para o controle da mastite e melhoria da qualidade do leite. Barueri, SP: Manole, 2007. 314 p.

SERVIÇO BRASILEIRO DE APOIO ÀS MICRO E PEQUENAS EMPRESAS SEBRAE. Programa PAS Leite: diferencial competitivo para produtores. Florianópolis, SC, 2015. Disponível em:<http://www.bibliotecas.sebrae.com.br/ chronus/ARQUIVOS_CHRONUS/bds/bds.nsf/bcdf15de0fca0f40384009da0e52e5e 1/ \$File/5389.pdf >. Acesso em: 12 ago. 2016.

SILVA, V. N.; RANGEL, A. H. N.; NOVAES, L. P.; BORBA, L. H. F.; BEZERRIL, R. F.; LIMA JÚNIOR, D. M. Correlação entre a contagem de células somáticas e composição química no leite cru resfriado em propriedades do Rio Grande do Norte. Revista do Instituto de Laticínios Cândido Tostes, Juiz de Fora, v. 69, n. 3, p. 165-172, mai/jun, 2014. Disponível em: <https://www.revistadoilct.com.

br/rilct/article/view/277/315> DOI: http://dx.doi.org/10.14295/2238-6416.v69i3.277.

STRADIOTTI JÚNIOR, D.; PENNA JÚNIOR, C. O.; CÓSER, A. C. Fatores que afetam a composição e a qualidade do leite. 2012. Produção Científica em formato eletrônico. Disponíveis em: <http://br.monografias.com/trabalhos3/fatoresafetam-composicao-do-leite/fatores-afetam-composicao-do-leite2.shtml>. Acesso em: 25 fev.2016.

VALLIN, V. M.; BELOTI, V.; BATTAGLINI, A. P. P.; TAMANINI, R.; FAGNANI, R.; ANGELA, H. L.; SILVA, L. C. C. Melhoria da qualidade do leite a partir da implantação de boas práticas de higiene na ordenha em 19 municípios da região central do Paraná. Semina: Ciências Agrárias, Londrina, v. 30, n. 1, p. 181-188, jan./mar. 2009. Disponível em: <http://www.uel.br/revistas/uel/index.php/ semagrarias/article/view/2661/2313>

DOI: http://dx.doi.org/10.5433/1679-0359. 2009v30n1p181.

VOGES, J. G.; THALER NETO, A.; KAZAMA, D. C. S. Qualidade do leite e a sua relação com o sistema de produção e a estrutura para ordenha. Revista Brasileira de Ciência Veterinária, v. 22, n. 3-4, p. 171-175, jul./dez. 2015. Disponível em: <http://www.uff.br/rbcv/ojs/index.php/rbcv/article/view/728/pdf> DOI: http://dx.doi.org/ 10.4322/rbcv.2016.009. 